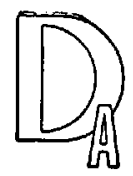

\title{
DOCUMENTACION ADMINISTRATILA
}

CENTRO DE FORMACION Y PERFECCIONAMIENTO DE FUNCIONARIOS

Madrid, enero de 1967

Núm. 109

Depósito legal : M 581/1958

\section{SUMARIO}

Páginas

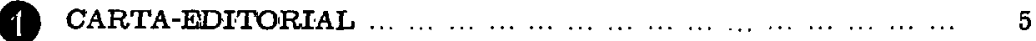

(2) ESTUDIOS:

- Coordinación entre órganos electivos y burocráticos en la Administración local, por Gustavo Vignocchi ..............

- Consideraciones en torno a la figura del segundo jefe, por

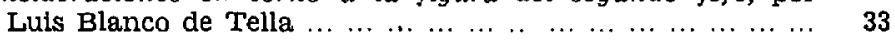

3 NOTAS:

- Observaciones a los concursos de méritos 1/1966 y 1/1967,

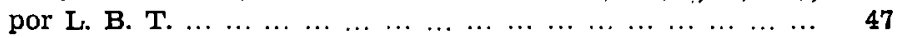

4 CENTRO DE INFORMACION ADMINISTRATIVA $\ldots \ldots \ldots \ldots$

5 DOCUMENTACION:

1. Crónica:

- Los reglamentos de la Seguridad Social, por Juan A. Sa-

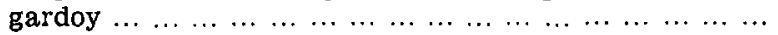


- La formación profesional en la industria inglesa, por José A. Colás Leblanc $\ldots \ldots \ldots \ldots \ldots \ldots \ldots \ldots$

2. Casos prácticos:

- Cuestionario de autovaloración personal relativo al estudio de la instalación, disposición y ambientación de las ofi-

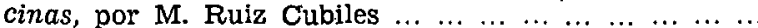

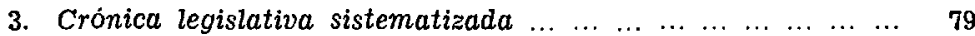

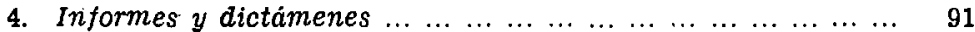

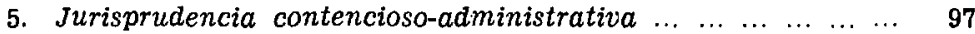

6. Bibliografia:

- Sintesis bibliográfica: Metodologia de la Ciencia del Derecho, por Karl Larenz ... ... ... ... ................... 103

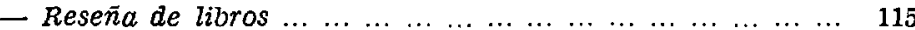

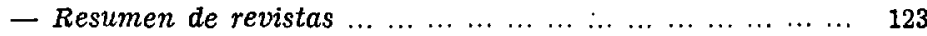

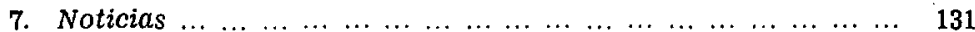

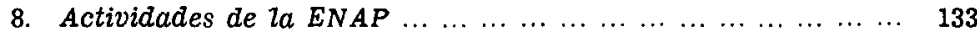

\section{APENDICE:}

- Fichas del contenido de Documentación Administratrya número 109.

- Hoja de sugerencia.

DOCUMENTACIÓN ADMINISTRATIVa NO SE IDENTIFICA NECESARIAMENTE CON LAS OPINIONES O JUICIOS QUE LOS AUTORES EXPONGAN EN USO DE LA LIBERTAD INTELECTUAL QUE SE LES BRINDA. 